\title{
Diego de Saavedra Fajardo y el regeneracionismo azoriniano: reescritura del inédito «La decadencia de España» ${ }^{1}$
}

\author{
Raúl Molina Sánchez \\ Universidad del Bósforo \\ rmolina.boun@gmail.com
}

Recepción: 22/07/2014, Aceptación: 03/10/2014, Publicación: 17/12/2014

\begin{abstract}
Resumen
La reescritura del artículo «La decadencia de Espańa» (1907) para su inclusión en el volumen Clásicos y Modernos (1913) convirtió a Diego de Saavedra Fajardo en su nuevo protagonista. El descubrimiento de la versión primitiva nos permite hoy explicar la relación entre el nuevo enfoque del texto y la elección de las ideas de Saavedra Fajardo para su argumentación.
\end{abstract}

Palabras clave

Saavedra Fajardo; Azorín; decadencia de Espańa; Diario de Barcelona; Clásicos y modernos; Empresas politicas; fatalismo; regeneracionismo

\begin{abstract}
Diego de Saavedra Fajardo and Azorin's regenerationism: the rewriting of the unedited article "La decadencia de España"

The article "La decadencia de España" (1907) rewritten by Azorín for publication in the book Clásicos y Modernos (1913) converts Diego de Saavedra Fajardo into his new protagonist. Today, the discovery of the original script allows us to explain the relationship between the perspective of new text and Saavedra Fajardo's choices for supporting his own ideas.
\end{abstract}

\section{Keywords}

Saavedra Fajardo; Azorín; Spanish decline; Diario de Barcelona; Clásicos y modernos, Empresas políticas; fatalism; spanish regenerationism

1. La presente investigación se enmarca dentro del Proyecto FF12011-22929 del Ministerio de Economía y Competitividad 
No es ninguna novedad hablar de la fuerte presencia de los clásicos en la obra de Azorín. Tampoco lo es decir que Saavedra Fajardo es uno de esos clásicos leídos y largamente meditados por el escritor levantino. La evolución de ese sinfronismo ${ }^{2}$ con el diplomático murciano se nos hace ahora un poco más comprensible a la luz del descubrimiento de un artículo inédito y desconocido por la crítica - publicado solo en las páginas de Diario de Barcelona del 26 de noviembre de 1907 bajo el título "La decadencia de España»—, hallado en la Hemeroteca Municipal de Barcelona. Olvidado entre las páginas de la prensa de ese año desde la aparición de una nueva versión en Clásicos y modernos (1913), el artículo que ahora rescatamos aporta información de gran valor y obliga a inferir nuevas conclusiones.

La presencia del pensamiento del diplomático murciano en la obra de Azorín no es visible desde los primeros trabajos, ni tampoco constante. Sí podemos decir que, a pesar del tono crítico usado con algunos autores considerados canónicos — ya desde la publicación de Moratín (1893)—, Saavedra Fajardo, junto a otros clásicos como Gracián, Jovellanos o el propio Montaigne, goza del respeto y la admiración del levantino desde la primera lectura y es considerado un autor afín. Prueba de ello es el hecho de que le dedicara más de una veintena de artículos a lo largo de su carrera periodística, en los que lo sitúa como modelo filosófico, político o estilístico.

Hay cuatro grandes momentos en los que la figura del diplomático murciano se hace más evidente en los textos de Azorín: el primero de ellos en los compases iniciales del siglo xx, con referencias al autor de las Empresas políticas en sendos capítulos de El alma castellana (1900) y El político (1908); el segundo, a partir de 1912 y hasta 1916, cuando Azorín empieza a hacer difusión de la figura y el pensamiento del prosista murciano en artículos de prensa; la tercera llegará en los años 1921 y 1922, y se caracteriza por un análisis profundo de la obra y las ideas de Saavedra Fajardo, cuyas conclusiones serán retomadas en otro grupo de artículos publicados entre 1943 y 1961, que forman la cuarta y última etapa. Estos últimos son de menor interés, debido a que no hay aportaciones nuevas sino simple reiteración, e incluso usos forzados, de lo ya expuesto anteriormente.

Las dos versiones de «La decadencia de España» (la redactada en 1907 —que a partir de ahora denominaremos DE 1 - y la incluida en Clásicos y Modernos, en 1913 - que denominaremos $\mathrm{DE}^{2}$ ) se sitúan, respectivamente, en el primero y segundo de esos momentos, por lo que será conveniente analizar las reflexiones que Azorín hace sobre el pensamiento saavedriano en cada una de esas etapas. Se podría conjeturar que el joven Martínez Ruiz leyó la obra del tratadista político murciano por vez primera en alguno de los dos volúmenes de la Idea de un príncipe politico cristiano, editados en 1786, que se conservan en la biblioteca familiar de la Casa-Museo Azorín, en Monóvar, pero no tenemos pruebas certeras

2. Utilizamos aquí la terminología que de Goethe toma Ortega para definir ese constante flujo de ideas entre Azorín y los clásicos. Vid. José Ortega y Gasset [2004: 299 y ss.]. 
del momento en el que se lleva a cabo la lectura de esta obra hasta la redacción de Los hidalgos (luego El alma castellana). ${ }^{3}$ Allí se aportan una serie de notas bibliográficas que permiten fechar esa recepción en tornoa 1900, año de la publicación de estas obras de juventud. Saavedra Fajardo aparece de nuevo en la fase de preparación de El político, en la segunda mitad del año 1907. Desde el verano de ese año y hasta febrero del siguiente, una convalecencia mantendrá apartado al autor de su frenética actividad periodística y del recién estrenado escaño parlamentario, como nos confirman dos cartas enviadas a Maura. ${ }^{4}$ En la segunda de ellas, de febrero de 1908, Azorín certifica la lectura de Saavedra Fajardo en los meses anteriores.

La fecha de redacción del artículo que aquí exhumamos coincide con ese paréntesis de intensa lectura y reflexión, previo a la escritura de El político. Pese a ello, el nombre de Saavedra Fajardo no aparece en DE¹. Sabemos, además, que uno de los libros leídos, tanto en ese momento como en el período de preparación de El alma castellana, es la Biblioteca española económico-política ${ }^{5}$ concretamente el tomo tercero, del que se conserva, también, un ejemplar en la biblioteca familiar de la Casa-Museo Azorín. La relación entre esta lectura y $\mathrm{DE}^{1}$ es evidente, puesto que de allí se extraen algunos datos estadísticos del arbitrista Martínez de la Mata que vienen a reforzar la argumentación del artículo que aquí rescatamos. Es interesante mencionar que en este tratado de política económica, Juan Sempere y Guarinos dedica un capítulo entero a la exposición de las ideas de Saavedra Fajardo, a pesar de lo cual, insistimos, son omitidas en el texto azoriniano de 1907. A lo largo de más de cuarenta páginas, el economista levantino expone las teorías materialistas ${ }^{6}$ saavedrianas sobre la decadencia de España - a partir del análisis de las Empresas políticas. Estas habían sido ya recogidas en «La hacienda» — capítulo primero de El alma española — y, seis años más tarde, iban a ser utilizadas de nuevo por Azorín, esta vez como base argumentativa de la nueva versión del artículo.

La coincidencia del capítulo dedicado a Saavedra Fajardo en el mismo volumen del que se toman los datos de Martínez de la Mata para la redacción de $\mathrm{DE}^{1}$, así como el contenido de la segunda de las cartas a Maura, nos lleva

3. Como sabrán los lectores de Azorín, El alma española asume el contenido de Los hidalgos, al que ańade un capítulo relativo al siglo xviII.

4. Las cartas se pueden consultar en José Ferrándiz Lozano [2009:290-292].

5. Juan Sempere y Guarinos [1801-1821].

6. Usamos aquí la terminología azoriniana de $\mathrm{DE}^{2}$, que distingue entre teorías materialistas, espirituales e idealistas para explicar las causas de la decadencia.

7. Vid. Azorín [1959a: 579 y ss.]. Como sugieren las notas bibliográficas al final de «La hacienda", algunas ideas que también estarán en el texto de 1913 (el perjuicio de las alcabalas, el problema del descenso demográfico o el del abandono de los campos, entre otros), habrían sido leídas con anterioridad en Saavedra Fajardo y Sempere y Guarinos, quien, a su vez, las habría recogido de los textos y reflexiones incluidos en Pedro Rodríguez de Campomanes [1805]. 
a pensar en una hipotética lectura de la obra del diplomático murciano en los momentos inmediatamente anteriores a esa primera escritura del artículo. En cualquier caso, de lo que no cabe duda es de que, en ese momento, Saavedra Fajardo no era un autor desconocido para Azorín y, sin embargo, la referencia a su pensamiento en los artículos periodísticos del autor de Monóvar es inexistente. No parece exagerado postular que el tratadista murciano fuera visto, en esos primeros años de acercamiento a su obra, como un autor para eruditos, lo que explicaría su inclusión en El alma castellana al hablar del problema de España, pero no en $\mathrm{DE}^{1}$. La referencia a Saavedra Fajardo, a diferencia de otros escritores clásicos, como Gracián, cuyas ideas sí son difundidas y glosadas en la prensa, queda relegada a un contexto más especializado, como es el del ensayo.

No será hasta febrero de 1912, dentro de la serie "Andanzas y lecturas» — publicada en La Vanguardia desde octubre de 1911 — cuando Azorín le dedique al diplomático murciano su primer artículo periodístico, «La España de Saavedra Fajardo». La propia lectura de las primeras líneas pone de manifiesto la voluntad de introducir biográficamente al personaje: «Nació don Diego de Saavedra Fajardo en 1584; murió en 1648. Fue su patria Algezares, pueblecillo cercano a Murcia. Compuso varios libros: de política, de crítica literaria, de historia..... ${ }^{8}$ Este artículo aparece recopilado en el volumen Lecturas españolas, publicado el mismo año de 1912, al que seguirían más tarde Clásicos y modernos (1913), Los valores literarios (1913) y Al margen de los clásicos (1915); todos con esa misma voluntad divulgativa, no solo en relación a Saavedra Fajardo, sino a los clásicos en general. El cambio de actitud respecto a los autores canónicos puede ayudar a entender la aparición en $\mathrm{DE}^{2}$ de ideas que, aunque ausentes en $\mathrm{DE}^{1}$, habían sido ya expuestas en «La hacienda». De este modo, $\mathrm{DE}^{1}$ deja de ser, simplemente, un extraño paréntesis en la continuidad ideológica existente entre los textos de 1900 y 1913 y deviene un texto clave para la comprensión de la evolución del pensamiento azoriniano.

Las particularidades de $\mathrm{DE}^{1}$ son varias. Si nos ceñimos a las diferencias con $\mathrm{DE}^{2}$, resulta evidente, como ya se ha dejado entrever, la disparidad en las referencias bibliográficas. Pero este dista de ser el único desajuste entre ambos textos: una primera lectura rápida nos dará ya a entender que la redacción de 1907 y la de 1913, si bien coinciden en el tema y el título del artículo, difieren bastante en todo lo demás. No estamos ante una variación del mismo artículo sino ante la reescritura, con vistas a la publicación del volumen Clásicos y Modernos, del texto de 1907, que quedó olvidado y es desconocido actualmente.

La lectura de las dos redacciones muestra los distintos caminos que toma el desarrollo del mismo tema de la decadencia. Al inicio de $\mathrm{DE}^{1}$, Azorín constata el declive de España a partir de la observación del paisaje de Castilla. Para ello se

8. Azorín [1912] y también, bajo el título «Saavedra Fajardo» en [1959b: 555 y ss.]. 
vale, primero, de la imagen que de nuestro país se construye su contemporáneo, José María Salaverría, en un viaje emprendido a Burgos y sus alrededores. Esta visión queda plasmada en el libro Vieja España y Azorín la resume así:

[...] este país está muerto, bien muerto, y si algo hay en él que atrae es esa aureola misteriosa que parece que envuelve caserones y callejuelas; ese ambiente de un pasado glorioso que se respira aun en las viviendas más humildes. ${ }^{10}$

Es, por otra parte, una imagen que coincide con la que el propio escritor levantino evoca en sus viajes por la ruta de don Quijote y del Lazarillo, ${ }^{11}$ con la particularidad de que él, en lugar de tomar una ciudad grande como medida para la descripción de la involución sufrida por el país, pone la lupa sobre pequeños pueblos para llegar a las mismas conclusiones con más fuerza. Según Azorín, esta es la ventaja de fijarse en el detalle. Incluso lleva esta actitud hasta el extremo, mostrando a un individuo, Francisco de Quevedo, como ejemplo de esta trayectoria del esplendor hacia el declive. Al lector habitual de Azorín no le sorprenderá esta tendencia a lo intrahistórico, tan sutilmente introducida en este artículo. A partir de la reconstrucción de estos pequeños pueblos en un pasado próspero, el artículo se convierte en una suerte de ubi sunt.

Todos estos pueblos y ciudades fueron un día el corazón de Castilla, de una Castilla rica, poderosa, esplendorosa. Al recorrerlos, el viajero evoca aquel esplendor y trata de explicarse cómo el poderío de antaño se disipó y se convirtió en decadencia y ruinas. [Ídem]

Las palabras de Gracián señalando la imposibilidad de encontrar en esa época «un Grande de España desempeñado» o «un real de a ocho en Castilla» ${ }^{12}$, así como los datos estadísticos tomados, no sin cierta desconfianza, de Martínez de la Mata, sirven para constatar el grado extremo de pobreza al que llegó el país. ${ }^{13}$ Es remarcable que Azorín solo se refiera al economista del siglo XviI para citar esos datos concretos o para hacer referencia a una de sus tesis principales —el perjuicio de lo extranjero para el país - con el fin de desprestigiar a los arbitris-

9. José Ma Salaverría [1907]

10. Azorín [1907]

11. Las crónicas de la primera ruta quedaron reseñadas, primero en las páginas de El Imparcial y más tarde en el libro La ruta de Don Quijote; las de la segunda tuvieron su espacio en Diario de Barcelona, en 1909.

12. Para esta y las citas siguientes, vid. Azorín [1907]; para la cita original de Gracián, vid. Baltasar Gracián [2011: 976].

13. Los mismos datos sobre la caída de la industria textil se encuentran también citados en el ya mencionado capítulo de El alma castellana (vid. nota 7) y, según Sempere Guarinos, pertenecen al "Octavo Discurso» del Memorial de Francisco Martínez de la Mata. Azorín consultó estos datos en el volumen de Sempere y Guarinos, según lo prueban las anotaciones del autor de Monóvar en el ejemplar conservado en la biblioteca familiar así como en las notas bibliográficas de «La hacienda». Vid. Juan Sempere Guarinos [1804: 227]. 
tas, en cuanto a formuladores de las causas de esta decadencia. Azorín centra su artículo en este fin, adoptando una actitud burlona respecto a estos autores, a la vez que de resignación frente a la imposibilidad de encontrar una explicación científica. Algo bien distinto a lo que hiciera en el mencionado capítulo de $E l$ alma castellana y de lo que había de hacer en $\mathrm{DE}^{2}$, donde recuperará el deseo de entender las causas del declive por la vía más racional.

En efecto, desde su inicio, $\mathrm{DE}^{2}$ muestra la voluntad de buscar una explicación histórica al debilitamiento del país. Se reconocen en el texto algunas teorías antaño defendidas por los arbitristas — aunque sin mencionarlos-, como el papel definitivo de la guerra en la despoblación y la relación directa de esta con la decadencia; pero sobre todo los comentarios críticos de algunos autores del siglo XviII, como Campomanes o Sempere y Guarinos, de los que Azorín se siente muy cerca ideológicamente. Gracián y Saavedra son considerados por el autor de Monóvar como las máximas autoridades en cuanto a la exposición de las causas del ocaso español iniciado en el siglo Xvir. Ambos apuntan, también, a la guerra como raíz del proceso nefasto. Azorín se basa en pasajes de las Empresas políticas en los que trasluce el «vigoroso espíritu contra la guerra» ${ }^{14}$ del diplomático murciano y donde se enumeran las consecuencias de la misma: «la religión se muda, la justicia se perturba, las leyes se desobedecen, la amistad y el parentesco se confunden, las artes se olvidan, la cultura se pierde, el comercio se retira, las ciudades se destruyen y los dominios se alteran». ${ }^{15}$ Del mismo Saavedra Fajardo se toman todavía otros motivos para la explicación de la decadencia, como la conquista de América — que se relaciona, también, con la despoblación, el abandono del trabajo y la ociosidad del país— o la expulsión de los moriscos: "Como a vencidos se les trató durante su permanencia en Espańa: como a conciudadanos debió habérseles tratado» — resume Azorín en el artículo—, porque «se atendió con esto más a conservar pura la nobleza, que a la paz y al bienestar de la nación». ${ }^{16}$

Jovellanos y Cabarrús desarrollan estas mismas ideas en el siglo XvıII. Citando a Jovellanos, se vuelven a plantear las consecuencias de la conquista: «mientras la población y la opulencia de las ciudades subía como la espuma, la deserción de los campos y un débil cultivo descubrían el frágil y deleznable cimiento de tanta gloria». ${ }^{17}$ Cabarrús "deplora que en guerreras empresas se gasten enormes caudales, en tanto que se desatiende el fomento de la riqueza patria». En este sentido, recrimina a Carlos I y Felipe II los caudales gastados en la guerra mientras que «el primero no los tuvo para concluir la Acequia Imperial, y el segundo, para hacer navegable el Tajo»; también se queja Cabarrús de que, en su

14. Para esta cita y las siguientes vid. Azorín [1959: 757 y ss.]

15. Para la cita de Saavedra Fajardo vid. Diego de Saavedra Fajardo [1999: 832]

16. Azorín [1959b: 758]

17. Para la cita de Jovellanos vid. Jovellanos [1997: 311]. 
época, no haya «un sólo ofrecimiento para los canales de Aragón o de Castilla, para los caminos y demás obras públicas de inmensa utilidad». ${ }^{18}$

Ganivet recupera de nuevo, en el siglo XIX, la crítica de la conquista: «Establecieron los Reyes Católicos la organización política de España; completaron esta obra con una restauración intelectual. Faltó una tercera restauración: la material». Y, a continuación, especifica a qué se refiere con esta última: «Debieron Fernando e Isabel fomentar la agricultura, la industria, el comercio; no pudieron hacerlo: se interpuso entre el propósito y la obra, el descubrimiento de América». Para Azorín, no solo la restauración material no se llevó a cabo, sino que la política y la intelectual fueron solo aparentes.

Los autores citados vienen a corroborar la continuidad de las teorías expuestas por Gracián y Saavedra. A estas se añaden las ideas tomadas de Cadalso — de carácter espiritual, según Azorín-y que se resumen en una sola frase de la obra del gaditano: «Desde el siglo XvI, hemos ido perdiendo los españoles el terreno que algunas otras naciones han adelantado en ciencias y artes», ${ }^{19}$ efecto de la ignorancia científica, la falta de curiosidad intelectual y de cuidado a la educación, la palabrería como método argumental y la discusión sobre asuntos banales.

La última autoridad citada será Larra, cuya teoría idealista basa la decadencia en «no habernos incorporado los españoles al movimiento de renovación intelectual iniciado con la Reforma». ${ }^{20}$

Algo misterioso e intangible envuelve toda la argumentación de $\mathrm{DE}^{1}$, mientras que en $\mathrm{DE}^{2}$ se exhibe una reflexión exhaustiva del tema a partir de la lectura de los pensadores clásicos que se han ocupado de él. Las conclusiones debían ser harto distintas. En $\mathrm{DE}^{1}$, Azorín atribuye la decadencia de España a la teoría de la fatalidad, como demuestran las últimas líneas del artículo:

[...] la verdad no hay que buscarla en estos o aquellos accidentes históricos; la verdad es que los pueblos nacen, se desarrollan y mueren fatalmente; que una fatalidad, que un destino inexcusable, que algo que no se puede determinar y que es independiente de toda fuerza y voluntad humana, hace que este pueblo, que es ahora floreciente y poderoso, esté abatido y pobre dentro de un siglo, y que aun dentro de una misma nación la pujanza, la vitalidad, que unas comarcas han dejado de tener, pasen a otras y les proporcionen el bienestar y la riqueza.

El destino es propuesto como único responsable de la situación en la que se encuentra la España de principios del siglo Xx. Muy distinta es la conclusión a la que se llega en $\mathrm{DE}^{2}$ :

no ha logrado jamás España una época de verdadero y sólido esplendor. «Un relám-

18. Para la cita de Cabarrús, vid. Cabarrús [1973: 80].

19. Para la cita de Cadalso, vid. Cadalso [2000: 232].

20. La idea desarrollada puede leerse en Larra [2000: 433 y ss.] 
pago» ha dicho Jovellanos que duró la gloria de España. Acaso es eso mucho. Nunca gozó España de una firme, estable, honda organización.

Aquí el tono es menos intuitivo, más pragmático. La exposición de las causas materiales, espirituales e idealistas de la decadencia, tomadas del pensamiento de los clásicos espańoles, apunta ahora hacia la responsabilidad de la mala gestión de los distintos gobernantes de nuestro país y, en última instancia, al factor humano. Como se apuntaba más arriba, la clave del nuevo enfoque del problema está en el proceso de recuperación de los clásicos que va desarrollando Azorín a finales de la primera década del siglo xx y que se hace visible desde los primeros textos de la serie «Andanzas y lecturas». Muchos de esos artículos pero también otros, aunque menos importantes en número, publicados en $A B C$ y Diario de Barcelona - pasarán a engrosar el volumen Lecturas españolas, cuyo epílogo es una suerte de versión preliminar de $\mathrm{DE}^{2}$.

Los títulos de algunos de los artículos de la serie «Andanzas y lecturas» — «La España de Cadalso», "Las ideas de Larra» o el mismo "La España de Saavedra Fajardo»- dejan ya intuir el inicio de esta nueva perspectiva de reflexión sobre el problema de España, que tendrá como resultado la enmienda de la versión primitiva del artículo que nos ocupa. Dos de los autores clásicos que desfilan por las páginas de "Andanzas y lecturas» y Lecturas españolas, son los primeros en matizar, allá por el siglo XviI, la conclusión determinista de $\mathrm{DE}^{1} \mathrm{y}$, por ello, constituyen la base de la argumentación de $\mathrm{DE}^{2}$. Azorín lo explica así en el segundo párrafo:

Las opiniones de Gracián y de Saavedra Fajardo sobre la decadencia de España son sintomáticas; se trata de dos de los más insignes pensadores del siglo xviI; representan con sus juicios una corriente ideológica que entonces se inició y que ha de llegar sin interrumpirse hasta nuestros días; hasta nuestros días, en que un gran pensador — don Joaquín Costa $-{ }^{21}$ ha de dar una forma pasional, dramática, a esa aspiración secular.

Esta corriente ideológica no es otra que la del regeneracionismo y Gracián y Saavedra, sus precursores. El matiz que introducen ambos en el determinismo histórico consiste en considerar el papel del hombre en su destino y la capacidad que tiene de, si no cambiarlo, "prevenir la infalible declinación de una inquieta rueda». ${ }^{22}$ Esa rueda, como explica Azorín en uno de los textos dedicados a Gracián en Lecturas españolas, ${ }^{23}$ "es todo: el Universo, el Mundo, la Humanidad, los

21. Joaquín Costa Martínez (1846-1911) fue el máximo representante español del Regeneracionismo.

22. Se refiere a la rueda de la diosa Fortuna.

23. Se trata del retrato de Gracián incluido en el capítulo final «Retratos de algunos malos espańoles y de un mal español honorario", de Lecturas españolas que, según nota de Angel Cruz Rueda, Azorín añadirá en la edición de 1920. Vid. Azorín [1959b: 637 y ss.]. A pesar de que la explicación sea posterior, el concepto está ya en el artículo de 1913. Vid. Gracián [2011: 88-89]. 
hombres»; y, también, los pueblos. Gracián acepta que «todo móvil inestable tiene aumento y declinación» pero emplaza al individuo a estar preparado para afrontar esta última. Esa es la responsabilidad humana que no se podrá eludir o esconder tras un argumento determinista. También en Saavedra Fajardo leerá el alicantino la misma lección. En el ya citado artículo de 1912 — «La España de Saavedra Fajardo"— Azorín se ocupa, casi por completo, de esta cuestión. Analiza allí el determinismo del autor murciano, y cita de las Empresas políticas:

Ninguna cosa permanece en la naturaleza. Esas causas seguidas de los cielos nunca paran; y así tampoco los efectos que se imprimen en las cosas, a que Sócrates atribuyó las mudanzas de las repúblicas. No son las monarquías diferentes de los vivientes o vegetables. Nacen, viven y mueren como ellos sin edad firme de consistencia; y así son naturales sus caídas. En no creciendo, descrecen. Nada interviene en la declinación de la mayor fortuna. El detenerla en empezando a caer, es imposible. ${ }^{24}$

La idea es asimilable a la de la rueda de Gracián y también lo será el matiz que se vincula a este determinismo. En el mismo artículo, de nuevo Azorín cita a Saavedra Fajardo:

Parte somos, y no pequeña de las cosas. Aunque se dispusieron sin nosotros, se hicieron con nosotros. [...] Menester es que obremos como si todo dependiera de nuestra voluntad. [...] No podemos romper aquella tela de los sucesos tejida en los telares de la eternidad, pero pudimos concurrir a tejerla. ${ }^{25}$

En todas las teorías expuestas en $\mathrm{DE}^{2}$ — y también en «La España de Saavedra Fajardo»-, las decisiones del hombre aparecen vinculadas al declive del país; pero, por la misma razón, nuevas decisiones podrían actuar en sentido contrario. La regeneración del país, la renovación que «da perpetuidad a los casos caducos por naturaleza $»^{26}$ —en palabras del tratadista murciano— podría ser la medida para contrarrestar la inevitable caída. La necesidad de esta intervención humana en el destino está también en la conclusión del epílogo a Lecturas españolas y se explica porque, como dice Azorín en el citado artículo de 1912, eufóricamente contagiado de la idea del pensador murciano, «entre las cosas que siguen la corriente eterna figuramos nosotros; nosotros con nuestra inteligencia, con nuestra voluntad».

El abandono de las tesis del inédito $\mathrm{DE}^{1}-\mathrm{y}$ por ende, su reescrituraadquiere sentido en el proceso de difusión de las ideas de Saavedra Fajardo en la prensa: el primer artículo destinado a dar a conocer la vigencia de su pensamiento, el de 1912, deja una huella notable en las conclusiones del volumen Lecturas españolas y tiene su efecto más visible en la reescritura de «La decadencia

24. Saavedra Fajardo [1999: 706].

25. Saavedra Fajardo [1999: 940].

26. Saavedra Fajardo [1999: 940]. 
de España», para la edición de Clásicos y modernos. La posibilidad de leer, hoy, el inédito que aquí recuperamos supone, frente a la reescritura de 1913, un ejemplo práctico, en primera persona, del valor de los clásicos y de la visión útil que Azorín tiene de ellos. «Un clásico es el reflejo de una sensibilidad moderna» - escribe el autor levantino en el «Nuevo prefacio» a la edición de Lecturas espanolas ${ }^{27}$; las ideas de Saavedra Fajardo son la base de $\mathrm{DE}^{2}$ porque, como se lee en la última frase de "La España de Saavedra Fajardo», «su espíritu es moderno» ${ }^{28}$. Y lo es porque sus aportaciones - y también las de Gracián, Jovellanos, Ganivet, Cadalso, Cabarrús o Larra y las de los demás clásicos que desfilan por Lecturas españolas - ayudan a entender el presente y proponen una solución de futuro. Desde ese punto de vista se hace perentoria la difusión de todos ellos, tarea a la que Azorín dedicará sus esfuerzos en los años siguientes.

27. Según nota de Ángel Cruz Rueda, Azorín introduce también este «Nuevo prefacio» en la edición de Lecturas españolas de 1920. Vid. nota 18.

28. Azorín [1959b: 555 y ss.]. 


\section{Apéndice \\ Transcripción del artículo inédito $\left(\mathrm{DE}^{1}\right)$}

\section{LA DECADENCIA DE ESPAÑA}

\section{Diario de Barcelona (26 de noviembre de 1907)}

D. José Ma Salaverría acaba de publicar un libro titulado Vieja España, con un prólogo de D. Benito Pérez Galdós. El señor Salaverría, escritor vasco, sale de su bello y floreciente pais y se marcha a Burgos. En Burgos, el autor va recorriendo las calles, callejuelas y plazas; entra en la Catedral; sale a las afueras de la ciudad, se detiene en un parador o mesón, llega hasta la Cartuja, y, en resolución, el señor Salaverría trata de empaparse del ambiente de esta vieja tierra castellana, conversando con los hidalgos que el acaso le depara y escudriñando interiores de iglesias y caserones. La impresión que el escritor vasco saca de sus andanzas es bien triste: este país está muerto, bien muerto, y si algo hay en él que atrae es esa aureola misteriosa que parece que envuelve caserones y callejuelas; ese ambiente de un pasado glorioso que se respira aun en las viviendas más humildes.

El autor de Vieja España, para darnos una impresión de Castilla, ha ido a una ciudad grande, a la capital de una comarca y apenas ha salido de ella y de los campos que la circundan. La experiencia hubiera sido mucho mejor, más concluyente, visitando algunos de esos pueblos y pequeñas ciudades perdidas en la meseta castellana $o$ en las estepas manchegas: pueblos y pequeñas ciudades que tuvieron una época de esplendor, en los cuales vivieron grandes señores y que hoy se nos muestran pobres y desiertos. Quien escribe estas lineas ha hecho algunas de esas excursiones; una de ellas fue a la capital del "antiguo y conocido Campo de Montiel»", según la frase de Cervantes en el Quijote: o sea Villanueva de los Infantes. Esta es una de las ciudades más interesantes de la tierra manchega; cerca de ella se encuentra el pueblecillo de la Torre de Juan Abad, del cual era señor Quevedo. Desde este pueblo, sintiéndose ya enfermo de muerte, vino el gran satírico a morir a Villanueva de los Infantes. En Villanueva hay anchos caserones con trazas de palacio, casas magnificas, que tienen en su centro patios rodeados de columnetas. Quevedo no vino a morir en ninguno de estos palacios; murió en una casa pequeña, sencilla, y en una estancia que tenía tan solo una angosta ventanita. ¿Cómo este hombre, que era una de las primeras figuras intelectuales de España y que también habia jugado tanto papel en los negocios públicos, murió en esta camarilla mezquina y pobre y no fue alojado en un palacio por alguno de los nobles de Villanueva?

Otra de las excursiones realizadas por el autor de este articulo, fue la que hizo siguiendo las huellas del Lazarillo de Tormes. Lázaro y el ciego salen de Salamanca y se detienen en un lugar Ilamado Almorox; desde aqui marchan a Escalona; en Esca-

29. Cervantes [2005: 35]. 
lona Lázaro abandona al ciego y va a Torrijos. De Torrijos se llega hasta Maqueda, que es donde sirvió al lacerado clérigo; dos o tres meses permaneció en Maqueda y de alli fue a parar a Toledo, donde le sucedieron las últimas aventuras que el autor del libro nos cuenta. Todos estos pueblos y ciudades fueron un día el corazón de Castilla, de una Castilla rica, poderosa, esplendorosa. Al recorrerlos, el viajero evoca aquel esplendor y trata de explicarse cómo el poderío de antaño se disipó y se convirtió en decadencia y ruinas.

He aqui un problema histórico, que es y será por mucho tiempo de viva actualidad. Si abrimos la Biblioteca española económico-politica, publicada a principios del siglo XIX por D. Juan Sempere y Guarinos, veremos que todos los economistas antiguos coleccionados en ella tratan de desentrañar las causas de la rápida decadencia de la nación. "Burgos, que habia tenido más de 6.000 vecinos ricos — dice Martínez de la Mata-, quedó reducida a 600; Medina del Campo, de más de 5.000, muy ricos y comerciantes, a 500, pobres y jornaleros; Sevilla tuvo más de 3.000 telares de seda, en que se ocupaban sobre 30.000 personas, y ya no se encontraban más de $60 »^{30}$. Repasando todos estos datos, encontramos un poco inverosimil el que fuera tanta la decadencia o hubiera sido antes tanto el esplendor. Pero, en fin, ello es que Castilla fue poderosa durante un periodo, más o menos largo, del siglo XVI, y que al acabar esta centuria y comenzar la decimoséptima, ya el decaimiento se inicia. No es posible imaginar el grado de pobreza a que esta noble tierra llegó. Baltasar Gracián, en su Criticón, parte II, capitulo II, enumera algunos grandes prodigios: entre ellos se encuentran el hallar un "Grande de España desempeñado»", es decir, sin trampas, $y$ «un real de a ocho en Castilla». Estos solos datos, que hoy podriamos repetir con irrecusable actualidad, nos dan cabal idea del empobrecimiento de España. ¿Cuáles fueron sus causas?

Los economistas españoles de los siglos XVI y XVII son unos pobres fantaseadores; ninguno de ellos acierta a ver la realidad; llenan sus libros de las más absurdas fantasias; aceptan de buen grado las más estupendas especies; y, en resolución, sus obras son un tejido de incongruencias y desvarios. Entre ellos, unos, por ejemplo, achacan la inexplicable ruina del pais a la extracción de la plata y demás metales preciosos que los extranjeros hacen del reino (este es uno de los tópicos más favorecidos); otros dicen que los extranjeros se han apoderado de todos los pequeños oficios manuales $y$ van ganando un dinero que los naturales no ganan; no faltan unos terceros que achacan el mal a la multitud de irlandeses y de gitanos que vagan por el pais ${ }^{32} ; y$, en definitiva, como paradoja curiosa, don Pedro Fernández de Navarrete - que es el

30. Vid. nota 13 .

31. Vid. nota 12 .

32. Las acusaciones a los extranjeros por ocupar los trabajos y por la extracción de plata se pueden leer en el «séptimo discurso» del propio Martínez de la Mata, recogido en Pedro Rodríguez de Campomanes [1775-1777] y comentado en Juan Sempere y Guarinos [1804: 209-120]. La alusión a los irlandeses y los gitanos se puede leer en Fernández de Navarrete [1805: 78 y ss.]. 
más razonable de todos estos arbitristas - afirma en su Conservación de Monarquías que una de las causas del malestar nacional es "un número grande que hay de viudas muy ricas y muy poderosas" ${ }^{33}$ que han venido a vivir a Madrid, debiendo estar sosegadas en sus pueblos.

¿Qué pensar y decir de todo esto? La decadencia de España dio mucho que hablar a los antiguos y dará aún mucho que escribir a los modernos. Cada cual se ingenia para descubrir las causas del fenómeno. Y la verdad no hay que buscarla en estos o aquellos accidentes históricos; la verdad es que los pueblos nacen, se desarrollan y mueren fatalmente; que una fatalidad, que un destino inexcusable, que algo que no se puede determinar y que es independiente de toda fuerza y voluntad humana, hace que este pueblo, que es ahora floreciente y poderoso, esté abatido y pobre dentro de un siglo, y que aun dentro de una misma nación la pujanza, la vitalidad, que unas comarcas han dejado de tener, pasen a otras y les proporcionen el bienestar y la riqueza.

33. Fernández de Navarrete [1805: 19-20]. 


\section{Bibliografía}

Azorín, «La decadencia de España», Diario de Barcelona, 26 de noviembre de 1907.

—, «La España de Saavedra Fajardo», La Vanguardia, 13 de febrero de 1912.

—, Obras Completas, Vol. I, Ángel Cruz Rueda, Madrid, Aguilar, 1959a.

—, Obras Completas, Vol. II, Ángel Cruz Rueda, Madrid, Aguilar, 19596.

Cabarrús, Ángel de, Cartas sobre los obstáculos que la naturaleza, la opinión y las leyes oponen a la felicidad pública, José Antonio Maravall, Madrid, Castellote, 1973.

Cadalso, José, Cartas Marruecas; Noches lúgubres, Rusell P. Sebold, Madrid, Cátedra, 2000.

Cervantes, Miguel de, El Quijote, Francisco Rico, Madrid, Real Academia Española, 2005.

Fernández de Navarrete, Pedro, Conservación de Monarquias, Madrid, Imprenta de D. Tomás Alban, 1805.

Ferrándiz Lozano, José, «Convalecencia y creación: El Político (1908)», Azorín testigo parlamentario. Periodismo y politica de 1902 a 1923, Madrid, Congreso de los Diputados, 2009.

Gracián, Baltasar, Obras Completas, Santos Alonso, Madrid, Cátedra, 2011.

Jovellanos, Gaspar Melchor de, Espectáculos y diversiones públicas; Informe sobre la ley agraria, Guillermo Carnero, Madrid, Cátedra, 1997.

LARra, Mariano José, Fígaro: colección de artículos dramáticos, literarios, políticos y de costumbres, Alejandro Pérez Vidal, Barcelona, Crítica, 2000.

Ortega y Gasset, José, Obras completas, Vol. II, Madrid, Taurus, 2004.

Rodríguez de Campomanes, Pedro, Apéndice a la educación popular, Madrid, Impr. de Sancha, 1805.

SaAvedra Fajardo, Diego de, Empresas politicas, Sagrario López Poza, Madrid, Cátedra, 1999.

Salaverría, José María, Vieja España. Impresión de Castilla, Madrid, Imprenta de los Sucesores de Hernando, 1907.

Sempere y Guarinos, Juan, Biblioteca española económico-politica, Madrid, Impr. de Sancha, 1801-1821.

—, Biblioteca española económico-politica, Tomo III, Madrid, Imprenta de Sancha, 1804. 